\title{
Fertility Intentions and Interest in Integrated Family Planning Services among Women Living with HIV in Nyanza Province, Kenya: A Qualitative Study
}

\author{
Elizabeth K. Harrington, ${ }^{1}$ Sara J. Newmann, ${ }^{1}$ Maricianah Onono, ${ }^{2}$ \\ Katie D. Schwartz, ${ }^{1}$ Elizabeth A. Bukusi, ${ }^{2}$ Craig R. Cohen, ${ }^{1}$ and Daniel Grossman ${ }^{1,3}$ \\ ${ }^{1}$ Department of Obstetrics, Gynecology and Reproductive Sciences, University of California, San Francisco, CA 94612, USA \\ ${ }^{2}$ Centre for Microbiology Research, Kenya Medical Research Institute, Nairobi, Kenya \\ ${ }^{3}$ Ibis Reproductive Health, 1330 Broadway, Suite 1100, Oakland, CA 94612, USA
}

Correspondence should be addressed to Daniel Grossman, dgrossman@ibisreproductivehealth.org

Received 20 February 2012; Accepted 21 May 2012

Academic Editor: Jean R. Anderson

Copyright ( 2012 Elizabeth K. Harrington et al. This is an open access article distributed under the Creative Commons Attribution License, which permits unrestricted use, distribution, and reproduction in any medium, provided the original work is properly cited.

\begin{abstract}
Despite increasing efforts to address the reproductive health needs of people living with HIV, a high unmet need for contraception exists among HIV+ women in sub-Saharan Africa. This study explores the fertility intentions and family planning (FP) preferences of Kenyan women accessing HIV treatment. We conducted 30 semistructured interviews and qualitatively analyzed the data with a grounded theory approach. Fears of premature death, financial hardship, and perinatal HIV transmission emerged as reasons for participants' desire to delay/cease childbearing. Participants strongly identified FP needs, yet two-thirds were using male condoms alone or no modern method of contraception. Women preferred the HIV clinic as the site of FP access for reasons of convenience, provider expertise, and a sense of belonging, though some had privacy concerns. Our findings support the acceptability of integrated FP and HIV services. Efforts to empower women living with HIV to prevent unintended pregnancies must expand access to contraceptive methods, provide confidential services, and take into account women's varied reproductive intentions.
\end{abstract}

\section{Introduction}

In the last decade, it has been increasingly recognized that global HIV/AIDS efforts often fail to address the reproductive health—and specifically family planning (FP)—needs of people living with HIV [1]. The need for an integrated approach to reproductive health and HIV was formally acknowledged as early as the 1994 International Conference on Population and Development [2] and has since generated substantial policy support and academic interest [3-5]. Yet disconnected and "vertically oriented" HIV programs persist [6], largely the product of separate funding streams and what has been described more recently as the "PEPFAR effect," which refers to the consequences of restrictions on the US President's Emergency Plan for AIDS Relief(PEPFAR-) supported programs against using funding for family planning [7].
In sub-Saharan Africa (SSA), a region where reproductive-aged women account for the majority of people living with HIV [8], there also exists a high unmet need for contraception. Unintended pregnancies (unwanted or mistimed) are estimated to account for $14-58 \%$ of all pregnancies in SSA [9]. Recent evidence suggests an even higher burden of unintended pregnancy among women living with HIV. In a cohort of Ugandan women started on antiretroviral therapy (ART), 17\% became pregnant over the 2-year followup period, despite $93 \%$ not wanting or planning pregnancy. Additionally, among the women who did not desire children, only $14 \%$ were using a modern contraceptive method other than condoms [10]. Another study of South African pregnant women attending a prevention of parentto-child transmission (PPCT) clinic found that $84 \%$ of clients' pregnancies were unintended [11]. 
From both reproductive rights-based and public health perspectives, the prevention of unintended pregnancy among women living with HIV has significant implications for maternal and child health. The World Health Organization/United Nations Population Fund Glion Call to Action emphasized family planning as one of four critical elements of a comprehensive PPCT strategy [12], reflecting the evidence on the cost savings and demonstrated effectiveness of contraception in averting HIV-positive births [13, 14]. Improved access to contraception among this population is also expected to facilitate efforts to decrease maternal morbidity and mortality, as well as poor neonatal outcomes $[15,16]$.

The Kenyan government, consistent with international policy recommendations, has demonstrated a strong commitment to the need to improve systems linkages between reproductive health and national HIV programs, reflected in its recently developed national policy strategy for reproductive health and HIV/AIDS integration [17]. However, little research has yet evaluated the clinical effectiveness of integration. This qualitative study was conducted as part of formative research for a cluster-randomized controlled trial (RCT) comparing integrated family planning and HIV services with the existing referral-based model in Nyanza Province, Kenya with respect to contraceptive prevalence. Located in western Kenya bordering Lake Victoria, Nyanza Province has the highest HIV prevalence in Kenya, at $16 \%$ among women and 11\% among men [18]. According to the 2009 Demographic and Health Survey, 76\% of reproductiveage women in Kenya wanted to delay pregnancy at least 2 years or have no more children, while only $33 \%$ were using a modern contraceptive method [18].

Despite the growing body of literature on the complex reproductive desires of people living with HIV/AIDS [19], there exist few in-depth studies set in Kenya and even fewer on people's attitudes towards integrated FP-HIV services [20]. This study sought to explore reproductive intentions, contraceptive experience, and family planning preferences among women accessing HIV care and treatment in Nyanza Province. Our aim was to gain a better understanding of HIV-positive women's experience and needs in order to guide efforts to reduce unmet need for contraception within this population, in part through designing the FP-HIV integrated service model for use in the cluster RCT.

\section{Methods}

2.1. Sites. This qualitative study was conducted between July and September 2009 in parallel with the baseline data-collection phase of the cluster RCT described above, that is, before integration took place. Participants were recruited from 11 public sector HIV clinics taking part in the cluster RCT in Kisumu East, Migori, Nyatike, Rongo, and Suba Districts of Nyanza Province; 1 dispensary, 8 health centers, 1 subdistrict hospital, and 1 district hospital were included in rural and periurban areas. Qualitative interviews were conducted at each site in conjunction with a knowledge, attitudes, practices, and behavior (KAPB) survey.
All sites were supported by Family AIDS Care and Education Services (FACES), a collaboration between the University of California, San Francisco (UCSF), and the Kenyan Medical Research Institute (KEMRI). This study was approved by the ethical review boards of KEMRI and UCSF.

2.2. Eligibility. Eligible participants were nonpregnant and nonsterilized, HIV-positive women aged 18-45 who were accessing care at FACES-supported HIV clinics. A convenience sample of KAPB survey respondents was invited to participate in an interview immediately after survey completion; each participant provided voluntary written informed consent and received a reimbursement of approximately USD \$2.50 for their time and travel.

2.3. Open-Ended Interviews. Thirty open-ended interviews were conducted to explore female clients' fertility intentions and family planning preferences in the context of integration of FP services into HIV care and treatment. Interviews were conducted in participants' first language (DhoLuo or Kiswahili) by a trained female interviewer. Each interview lasted approximately 60 minutes and was based on a semistructured interview guide. All interviews were audio recorded.

2.4. Data Analysis. Interviews were transcribed and translated into English. Data were managed in Atlas-ti 5.2 (Scientific Software Development, Berlin, Germany), and transcripts were coded and analyzed with a grounded theory approach [21], though unlike classic grounded theory the data were collected and analyzed sequentially. Three investigators independently conducted initial coding of the transcripts according to a codebook constructed from the interview guide content and a preliminary content analysis of the raw data; inductive codes based on the data were developed as concepts emerged. Each coded transcript was checked by a second investigator, and discrepancies were resolved through discussion and consensus. In the final analysis, codes and quotations were grouped to identify thematic trends and variant views. Quotes presented here are identified by the age of the participant, the number of living children she has, and her current contraceptive method, if any; multiple quotes from the same participant are identified as such. Nonnumerical quantifiers such as "the majority," "a minority," "almost all," and "a few," are used to frame various themes; where proportions of participants are quantified, it is for the purpose of highlighting specific points and is intended to be descriptive only.

\section{Results}

The mean participant age was 30 years, with a median of 29.5 years (Table 1$)$. The majority $(70 \%)$ were married or living with a man, and $8(27 \%)$ were in polygynous marriages. Among the 28 (93\%) women who had given birth, the mean number of live births was 4.6, with an average of 3.2 living children. One-third had begun an antiretroviral regimen. Eight $(27 \%)$ women were using a method of contraception 
TABle 1: Participant sociodemographic characteristics and current contraceptive use among 30 study participants in Nyanza Province, Kenya.

\begin{tabular}{|c|c|c|c|}
\hline & $N(\%)$ & Mean & Range \\
\hline Age & & 30 & $18-42$ \\
\hline $18-24$ & $6(20 \%)$ & & \\
\hline $25-34$ & $18(60 \%)$ & & \\
\hline $35-42$ & $6(20 \%)$ & & \\
\hline \multicolumn{4}{|l|}{ Marital status } \\
\hline Married or living with a man & $21(70 \%)$ & & \\
\hline Polygynous marriage & $8(27 \%)$ & & \\
\hline Widowed/inherited & $7(23 \%) / 4(14 \%)$ & & \\
\hline $\begin{array}{l}\text { Unmarried, not living with a } \\
\text { man }\end{array}$ & $2(7 \%)$ & & \\
\hline \multicolumn{4}{|l|}{ Education } \\
\hline Primary school or less & $25(84 \%)$ & & \\
\hline Secondary school & $5(17 \%)$ & & \\
\hline \multicolumn{4}{|l|}{ Literacy } \\
\hline $\begin{array}{l}\text { Reads with difficulty or not at } \\
\text { all }\end{array}$ & $17(57 \%)$ & & \\
\hline Reads easily & $13(43 \%)$ & & \\
\hline Number of live births, $N=28$ & & 4.6 & $1-11$ \\
\hline $\begin{array}{l}\text { Number of living children, } \\
N=28\end{array}$ & & 3.2 & $1-7$ \\
\hline Time since HIV diagnosis (years) & & 1.5 & $<1-4$ \\
\hline Currently on ART & $10(33 \%)$ & & \\
\hline \multicolumn{4}{|l|}{ Current contraceptive use } \\
\hline No modern method & $10(33 \%)$ & & \\
\hline Injectable & $7(23 \%)$ & & \\
\hline Combined oral contraceptives & $1(3 \%)$ & & \\
\hline Condoms only & $12(40 \%)$ & & \\
\hline Dual method use & $2(7 \%)$ & & \\
\hline
\end{tabular}

other than condoms, while $12(40 \%)$ were using condoms only, and $10(33 \%)$ were not using a modern contraceptive method.

3.1. Desire to Delay or Cease Childbearing. All but two participants wanted to delay pregnancy for at least two years or have no more children; of note, the women who desired a child within the next two years were both nulliparous. Of the 16 women who desired a future pregnancy, over half wanted to delay the pregnancy for 4-10 years. Several main themes emerged around participants' desire to delay or cease childbearing.

The perceived detrimental effects of pregnancy and childbirth on HIV-related poor health and immune status were frequently expressed concerns. One participant had been counseled that her CD4 count was too low to have a child; another woman who had recently given birth explained,

"I don't want to give birth soon because I am sick. The virus is ... destroying my blood so if I give birth very soon then my immunity goes down ..."

(P1: 29 years, 2 children, no modern method)

Related to concerns about deteriorating health, several women feared dying prematurely and spoke of uncertainty around the length of one's life in the context of caring for existing or future children as a reason to stop having children. Single relationship status, often synonymous with widowhood, was also a factor for several participants. Inherited by a brother-in-law according to some Luo people's custom after her husband died, one widow said,

"Before I tested HIV positive, I was at liberty, I
knew that even if one day I die it would just come
as my days were numbered by God, but with HIV
I felt that I would die prematurely and since their
[my children's] father was not there and I was
solely taking care of them it worried me. Before
then I was happy..." (P7: 39 years, 6 children,
injectable contraception)

The majority of participants considered the risk of transmitting HIV to a child in their fertility intentions, although a wide spectrum of knowledge existed around the likelihood of perinatal transmission. Many women had sophisticated understandings of prevention strategies, while others believed transmission inevitable: "because I am giving birth to them when I am sick, and they would also be born sick..." Some women described previous experiences of losing children to AIDS. A participant who had known her status for less than a year and already had five children said:

\section{"I have been worried about the child that I have now because of being HIV positive, whether the child is infected or not... I don't have the desire to have another child ... because I fear ... I am sick and I don't know my baby's future." (P26: 31 years, 5 children, male condom)}

Financial hardship, often related to poor health and subsequent inability to do strenuous labor or lack of support from a male partner, was also a common theme related to preventing future pregnancies. Many participants prioritized providing for existing children in the context of diminishing resources. One woman said, "nowadays when I go to the farm I can't work longer because I am weak and... I have no steady source of livelihood." Another woman who was concerned about providing for her children's education, despite her family's need for labor, reasoned,

"The family members do not like women to go for family planning. They ask... "why is a woman going for family planning, yet there is a huge parcel of land?" ...." (P22: 23 years, 3 children, injectable contraception)

3.2. Influences on Fertility Intentions. Participants cited health care providers as influences on their reproductive intentions more often than they mentioned family or other community members. Provider counseling contributed to a range of understandings of the risks associated with 
pregnancy and/or HIV transmission, which might have depended on the woman's health.

"Following the kind of counseling we get here at the clinic, one can just decide not to have another pregnancy if you are already infected. This is because the pregnancy lowers your immune system thereby making you vulnerable to other infections ...." (P9: 33 years, 4 children, male condom)

"... If you give birth, the health care providers try so hard to protect the child such that if you follow the counseling the children will just be okay. So even if you got HIV having only one child, you can go ahead and have more children." (P8: 23 years, 3 children, no modern method)

Although many participants spoke of joint decision making around fertility with partners, others had never spoken of their specific plans to delay or stop childbearing with partners. Albeit obliquely, some women discussed the complexity of their communication with men around reproductive issues, dually focusing on the woman as the final decision maker and the need to cement couple relationships by having a child:

\begin{abstract}
"If you don't have any child then you might be forced to have because you know it is the child that allows a woman to stay in a man's house. You will be forced to give birth even to two so that they can say that so-and-so gives birth, then after that you stop." (P12: 28 years, 2 children, male condom)
\end{abstract}

Family members and in-laws significantly influenced several women's reproductive intentions in both directions. A few women stated that their HIV status was the reason they had been advised against pregnancy. For example,

"We had discussed it with [my sisters], and they felt I shouldn't get another pregnancy ... They were saying that having another child would just give lots of problems to the child because the child will also have HIV." (P11: 32 years, 5 children, male condom/pill)

Another participant noted that her mother-in-law, who expected her to die of AIDS, "told me that I should not give birth because there is no one who will raise the children, because your husband is dead." Other participants felt a social imperative towards fertility. Feeling pressure by extended family to get pregnant again, a woman whose child had recently died said,

"You may tell [the relatives] that now you don't feel like having another child... They don't like it ... they tell you 'just continue to give birth you are still young." (P1: 29 years, 2 children, no modern method)

Another woman put it like this: "You know, it's good to have a child so that people don't look down on you."
3.3. Unintended Pregnancy. When discussing their most recent pregnancies, roughly half of women said their pregnancies had been desired or planned, and half were undesired, for reasons very similar to those discussed above. Narratives of unintended pregnancy centered on poor health and consequences to one's child(ren) rather than positive HIV status itself.

"During my last pregnancy I became very sick, and
when I eventually gave birth the baby also had
very poor health, [and] after one month the baby
died. That is when I learned of my HIV status...
Since my child died as a result of that I don't see the
need of getting another child...." (P20: 42 years,
2 children, no modern method)

Most participants expressed profoundly negative feelings when asked how they would react to a pregnancy now. Women also spoke of a sense of powerlessness around unintended pregnancy, which was linked to the belief that pregnancy occurs according to "God's plan." Almost a quarter spontaneously volunteered that they would try to procure an abortion if they learned they were pregnant, despite financial and potentially lethal consequences:

"I would contemplate abortion, but I also fear that I would lose my life in the process of abortion; however, I would seriously consider terminating the pregnancy." (P7: 39 years, 6 children, injectable contraception)

3.4. Contraceptive Experience. The vast majority of participants expressed a need for FP (27/30), though over twothirds were currently using male condoms only, or no modern method of contraception (Table 1). When women were asked which FP method they would prefer to use, injectable and implantable, followed by oral, methods were most frequently desired, and over half indicated that they would prefer tubal ligation then or in the future. Some women discussed the benefits of condoms as an FP method, either alone or in combination with another method to prevent sexually transmitted infections, while others focused on the pitfalls associated with negotiating condom use.

"You know at times you may want to use it [condom], but then your partner will think maybe you don't trust him, and you may end up infecting him." (P8: 23 years, 3 children, no modern method)

Women's choice to use or not use a particular contraceptive was strongly influenced by perceptions of method side effects, regardless of whether the side effects had been experienced personally or heard about from others. Most personally experienced side effects were associated with injectables and involved excessive or irregular vaginal bleeding. However, participants had heard about various methods causing infertility, drug reactions with ART, wasting, weakness and inability to work, as well as pain, other physical complications, and even death. One participant, 
who was using injectable contraception without her partner's knowledge since learning of her HIV status, spoke of his reasons for opposing FP use:

\section{"They [pills and injectables] may hinder you from giving birth later or you might even have another problem which may lead to you going for an operation ...." (P2: 26 years, 2 children, injectable contraception)}

3.5. Unmet Need. Though the majority of participants denied encountering any difficulties in accessing FP, many expressed an unmet need for contraception. Several accessrelated obstacles emerged in addition to health concerns, among which were unreliable stock of contraceptive methods and provider availability, inability of some providers to speak the local language, and distance to the clinic. Partner resistance to $\mathrm{FP}$ was another barrier to access participants mentioned, although many emphasized their own decisionmaking autonomy as "the one who will bear the burden." Several women spoke of using FP secretly, some risking separation or abandonment by their partners.

"The problem [regarding family planning] is at home. But once you turn your back there is no problem ... it is the person you are living with that causes the problem by saying that 'I don't want that'” (P1: 29 years, 2 children, no modern method)

3.6. Preference for Integrated Services. When asked where participants would prefer to access FP services, the majority stated a preference for the HIV clinic, and all but a few women preferred integrated FP-HIV services when this option was specifically proposed. Convenience and a sense of belonging at the HIV clinic were the most commonly mentioned advantages to integrated services. Many were already making trips to the HIV clinic for drugs and felt like an established "regular" there.

"[The HIV clinic] is the place where I come
and I get all the services without announcing my
problem elsewhere. I meet my need and I leave
for home." (P1: 29 years, 2 living children, no
modern method)

Other women preferred the HIV clinic as the site of FP access for reasons of provider expertise; the "good doctors who are educated" were able to avoid prescribing FP methods that may react with antiretroviral drugs and to provide more family-oriented counseling and services, thereby helping to protect children from HIV. Women mistrusted volunteers and community health workers ( $\mathrm{CHWs}$ ), who they perceived as lacking the necessary knowledge and training to provide FP. Participants preferred FP to be provided by trained clinicians.

Women's individual experiences accessing care at the various HIV clinic sites appeared to inform their perspectives on how integrated services might affect privacy concerns. One participant remarked on the potential for increased privacy around FP at the HIV clinic, as one was able to speak to a nurse one-on-one in this setting, whereas at the FP clinic several women may be counseled at the same time. The only woman to say she would refuse FP at the HIV clinic spoke of the need for clandestine FP services:

"Family planning is something secret ... I would like to get it from a different, private place." (P29: 30 years, 3 children, male condom)

Of note, this participant reported that her partner said he would leave her if he found out she was using an FP method other than condoms.

Similarly, the idea of accessing FP in a "mixed up" setting, that is, one that also served men, was simultaneously viewed as an advantage and disadvantage to integrated services. One woman wanted to access FP where there were only women, while another preferred the HIV clinic "because while we are waiting to go in men and women are counseled together." Two women admitted using injectable contraception without their partners' knowledge, and both preferred integrated services.

\section{Discussion}

This study provides insights into the fertility desires and family planning needs of a sample of Kenyan women accessing HIV care. It is among the first to specifically explore women's perspectives on FP-HIV integration, as increasing priority is placed on strengthening health systems globally. This contribution is particularly relevant, both in the context of the related cluster RCT as well as the wider efforts on FP-HIV integration, given the imperative to design integration interventions that take into account women's lived experiences. Our findings corroborate other studies' portrayal of the diversity and complexity of reproductive intentions among people living with HIV in sub-Saharan Africa, which are influenced by overlapping health-related, sociocultural, and socioeconomic factors [22-24]. Yet the value of qualitative, geographically-specific perspectives such as those generated in this study lies in their capacity to uncover nuances that are essential in informing both interventions and further research.

We observed a strong desire on the part of most participants to delay or cease childbearing, the reasons for which were often HIV-related. However, consistent with prior studies and the larger KAPB survey sample [25, 26], contraceptive prevalence was low. Though many women spoke of various barriers to FP access as presented above, a good number of participants did not provide a rationale for their "unmet need," that is, why they were not taking action to prevent pregnancy. This disconnect is salient given the substantial minority of participants who were ready to face significant costs to terminate a pregnancy. Abortion is legally restricted in Kenya, and unsafe abortion accounts for approximately $17 \%$ of maternal mortality in Eastern Africa $[27,28]$.

Many participants were not as forthcoming about systems-related sources of unmet need for contraception as expected based on formative research in the region [29]. 
For example, reports from the field as the cluster RCT continues suggest that user fees are a barrier to FP use [30], while only one participant in this study mentioned cost as an obstacle to access. Rather, fears of method safety and partner influence were more dominant themes. The significant role of men in reproductive decision making has been recognized in the literature for years [31, 32], leading many to call for interventions to increase male involvement in family planning programs. Yet, gendered power dynamics around contraception are, without question, complex. Our participants' narratives included mention of women's preference for injectables as a more easily concealed method; whether or not covert contraceptive use is being used as a "practical strategy to subvert male authority," [33] 16\% of married women in Nyanza Province use contraception without their partners' knowledge, and nearly half of all modern contraceptive users in Kenya are using injectable methods [18]. Though this study necessarily concentrated on women living with HIV, our findings suggest that the factors associated with unmet need for FP among HIV+ women may reflect the social, economic, and cultural circumstances of the women of Nyanza Province in general. Clearly, from a rights-based perspective, it is essential to work toward meeting all women's needs for contraception.

Though most women stated a strong preference for integrated FP-HIV services, concerns about privacy emerged. One could interpret these concerns in the context of covert contraceptive use, or the widespread belief among men in Kenya that contraception use leads to female promiscuity [18]. In contrast, a pilot study of integrated FP, ART, and Voluntary Counseling and Testing (VCT) services in Uganda revealed a preference for integration in part because women felt that attending sessions with male partners would help them change their partners' negative views on FP [20]. More research is needed to better understand how relationship and gender dynamics influence reproductive and contraceptive choice among women in sub-Saharan Africa.

In contrast with other research $[22,34]$, study participants made no mention of health care provider disapproval or stigma as a potential deterrent to accessing reproductive health services at the HIV care and treatment clinics or referral clinics. This reflects the results of recent interviews with providers at these same clinics, who strongly supported the reproductive rights of women living with HIV and their desire to have children when they want [35]. However, it should be noted that the majority of women had not accessed formal FP services since learning of their HIV status. Provider counseling, on the other handparticularly around the risk of perinatal HIV transmission and the effects of pregnancy on HIV disease-emerged as an influential factor on women's reproductive intentions in both directions. Additionally, women's lack of confidence in the ability of CHWs and volunteers to provide FP methods was notable, particularly in the setting of decades of research demonstrating the acceptability of programs such as community-based distribution of contraception in the region [36]. Our study's participants tended to associate CHWs with practitioners of traditional, or herbal, medicine. Women also placed a high value on obtaining care from those they viewed as legitimate medical professionals, as reflected in the finding that provider expertise at the HIV clinic was a major factor in participants' preference for accessing FP there. It is possible that this sample of women, who were already established in the medical system, were more concerned with credentials than other women in the community.

Fears of method side effects and other untoward effects, many of which would be considered misperceptions, significantly shaped women's reproductive choices among our participants. Such concerns are the leading reason for contraceptive nonuse in Kenya more broadly [18]. Furthermore, the desire for permanent or long-acting contraception surfaced frequently in our interviews, often among women who were currently using less effective methods or no modern FP method and expressed considerable fears regarding contraceptive methods. These findings suggest that addressing women's FP needs, including permanent and LARC methods, must incorporate balanced reproductive health and FP counseling for people living with HIV, as well as community-based education on method safety [37, 38]. Partially in response to these findings, the cluster RCT included a training focus on counseling about and provision of long-acting reversible contraception (LARC), as well as referral for surgical sterilization.

This exploratory study has several limitations. As with most qualitative studies, its sample size is small, and the study was not designed to produce findings that would be generalizable to other women living with HIV in Kenya or elsewhere in SSA. Instead, the aim was to provide deeper insights that could inform results from larger samples. The quantitative data describing our study participants is not intended to be representative of a broader population. In addition, study participants were already accessing HIV care; we did not include women living with HIV from the community who were not accessing HIV care or women of unknown HIV status, who may have had different perspectives. Given that these women were recruited from clinic sites and might have associated interviewers with care providers, there is also a risk of social desirability bias. Though theoretical saturation was reached around all main themes, some concepts, such as the desire for fertility within two years and the influence of cultural practices such as wife inheritance and polygyny on fertility intentions, could not be fully developed due to the small sample size. Finally, nuances of language and nonverbal communication strategies may have been lost or misinterpreted during the process of data transcription and translation.

Women living with HIV, like all women, should have access to highly effective methods to avoid unintended pregnancy. The integration of FP services into HIV care has been identified as a promising strategy to reduce unmet need for contraception among women living with HIV, and this study supports its acceptability. However, our findings emphasize that increasing access from the health systems perspective will not necessarily address other important determinants of access and choice, such as the balance of power in intimate relationships and fears regarding method safety. Despite these challenges, efforts to empower women 
living with HIV to prevent unintended pregnancies must expand access to all contraceptive methods, particularly long-acting and permanent methods. These efforts must also provide confidential, informed services that take into account women's varied reproductive intentions and needs.

\section{Acknowledgments}

This study was funded by grants from the Tides Africa Fund and the Bill \& Melinda Gates Foundation. A version of the paper was presented at Reproductive Health 2010, the annual meeting of the Association of Reproductive Health Professionals, the Society of Family Planning, and the Planned Parenthood Federation of America, on 24 September 2010. The authors are grateful to their colleagues Harriette Sande, Salome Ogola, and Douglas Okelloh for their respective assistance with study coordination, data collection, and transcription/translation. This paper is published with the permission of the Director, KEMRI.

\section{References}

[1] S. Gruskin, L. Ferguson, and J. O’Malley, "Ensuring sexual and reproductive health for people living with HIV: an overview of key human rights, policy and health systems issues," Reproductive Health Matters, vol. 15, no. 29, pp. 4-26, 2007.

[2] United Nations Population Fund (UNFPA), International Conference on Population and Development (ICPD) Programme of Action, United Nations Population Fund, Cairo, Egypt, 1995.

[3] J. Fleishman, Integrating Reproductive Health and HIV/AIDS Programs: Strategic Opportunities for PEPFAR, Center for Strategic and International Studies, Washington, DC, USA, 2006.

[4] R. Wilcher, W. Cates Jr., and S. Gregson, "Family planning and HIV," AIDS, vol. 23, supplement 1, pp. S1-S130, 2009.

[5] K. Angela, D. R. Bangsberg, G. Gray, R. S. Hogg, R. King, and C. L. Miller, "HIV, HAART, and Fertility in sub-Saharan Africa," AIDS and Behavior, vol. 13, supplement 1, pp. S1S112, 2009.

[6] C. Dickinson, K. Attawell, and N. Druce, "Progress on scaling up integrated services for sexual and reproductive health and HIV," Bulletin of the World Health Organization, vol. 87, no. 11, pp. 846-851, 2009.

[7] R. Wilcher, W. Cates Jr., and S. Gregson, "Family planning and HIV: strange bedfellows no longer," AIDS, vol. 23, supplement 1, pp. S1-S6, 2009.

[8] UNAIDS, "UNAIDS Report on the Global AIDS Epidemic," 2010, http://www.unaids.org:80/globalreport/Global_report .htm.

[9] H. W. Reynolds, B. Janowitz, R. Wilcher, and W. Cates, "Contraception to prevent HIV-positive births: current contribution and potential cost savings in PEPFAR countries," Sexually Transmitted Infections, vol. 84, supplement 2, pp. ii49-ii53, 2008.

[10] J. Homsy, R. Bunnell, D. Moore et al., "Reproductive intentions and outcomes among women on antiretroviral therapy in rural Uganda: a prospective cohort study," PLoS One, vol. 4, no. 1, Article ID e4149, 2009.

[11] T. J. Rochat, L. M. Richter, H. A. Doll, N. P. Buthelezi, A. Tomkins, and A. Stein, "Depression among pregnant rural
South African women undergoing HIV testing," Journal of the American Medical Association, vol. 295, no. 12, pp. 1376-1378, 2006.

[12] United Nations Population Fund (UNFPA), “The Glion Call to Action on Family Planning and HIV/AIDS in Women and Children," 2004, http://www.unfpa.org/public/publications/ $\mathrm{pid} / 1435$.

[13] H. W. Reynolds, B. Janowitz, R. Homan, and L. Johnson, "The value of contraception to prevent perinatal HIV transmission," Sexually Transmitted Diseases, vol. 33, no. 6, pp. 350-356, 2006.

[14] M. D. Sweat, K. R. O’Reilly, G. P. Schmid, J. Denison, and I. de Zoysa, "Cost-effectiveness of nevirapine to prevent mother-tochild HIV transmission in eight African countries," AIDS, vol. 18, no. 12, pp. 1661-1671, 2004.

[15] A. Duerr, S. Hurst, A. P. Kourtis, N. Rutenberg, and D. J. Jamieson, "Integrating family planning and prevention of mother-to-child HIV transmission in resource-limited settings," The Lancet, vol. 366, no. 9481, pp. 261-263, 2005.

[16] P. Brocklehurst and R. French, "The association between maternal HIV infection and perinatal outcome: a systematic review of the literature and meta-analysis," British Journal of Obstetrics and Gynaecology, vol. 105, no. 8, pp. 836-848, 1998.

[17] Republic of Kenya, National Reproductive Health and HIV/ AIDS Integration Strategy, National AIDS and STI Control Program (NASCOP) and the Division of Reproductive Health (DRH), Nairobi, Kenya, 2009.

[18] Kenya National Bureau of Statistics (KNBS) and USAID, Kenya Demographic and Health Survey 2008-09, 2010, http:// www.measuredhs.com/pubs/pdf/FR229/FR229.pdf.

[19] B. Nattabi, J. Li, S. C. Thompson, C. G. Orach, and J. Earnest, "A systematic review of factors influencing fertility desires and intentions among people living with HIV/AIDS: implications for policy and service delivery," AIDS and Behavior, vol. 13, no. 5, pp. 949-968, 2009.

[20] D. Asiimwe, R. Kibombo, J. Matsiko, and K. Harden, Study of the Integration of Family Planning and VCT/PMTCT/ART Programs in Uganda, Makerere Institute for Social Research and POLICY for USAID, 2005.

[21] K. Charmaz, Constructing Grounded Theory: A Practical Guide Through Qualitative Analysis, Sage, Thousand Oaks, Calif, USA, 2006.

[22] D. Cooper, J. Harries, L. Myer, P. Orner, and H. Bracken, “Life is still going on': reproductive intentions among HIV-positive women and men in South Africa," Social Science \& Medicine, vol. 65, no. 2, pp. 274-283, 2007.

[23] F. Laher, C. S. Todd, M. A. Stibich et al., "A qalitative assessment of decisions affecting contraceptive utilization and fertility intentions among HIV-positive women in Soweto, South Africa," AIDS and Behavior, vol. 13, supplement 1, pp. S47-S54, 2009.

[24] D. Cooper, J. Moodley, V. Zweigenthal, L. G. Bekker, I. Shah, and L. Myer, "Fertility intentions and reproductive health care needs of people living with HIV in Cape Town, South Africa: implications for integrating reproductive health and HIV Care services," AIDS and Behavior, vol. 13, supplement 1, pp. S38S46, 2009.

[25] A. Anand, R. W. Shiraishi, R. E. Bunnell et al., "Knowledge of HIV status, sexual risk behaviors and contraceptive need among people living with HIV in Kenya and Malawi," AIDS, vol. 23, no. 12, pp. 1565-1573, 2009.

[26] S. Newmann, D. Grossman, C. Blat et al., "Contraceptive use and receptivity to integration of family planning services into 
HIV care among HIV-infected men and women in Nyanza province, Kenya," in Proceedings of the Reproductive Health, Atlanta, Ga, USA, September 2010.

[27] World Health Organization (WHO), Unsafe Abortion: Global and Regional Estimates of the Incidence of Unsafe Abortion and Associated Mortality in 2008, World Health Organization, Geneva, Switzerland, 6th edition, 2011, http://www.who.int/ reproductivehealth/publications/unsafe_abortion/978924150 1118/en/index.html.

[28] United Nations Population Division, World Abortion Policies 2007, 2007, http://www.un.org/esa/population/publications/ 2007_Abortion_Policies_Chart/2007AbortionPolicies_wallchart.htm.

[29] K. Koh, "Suggestions for improving reproductive health care at FACES Clinics," Personal communication, 2006.

[30] G. A. Ong’udi, "Personal communication,” 2011.

[31] B. Wolff, A. K. Blanc, and J. Ssekamatte-Ssebuliba, "The role of couple negotiation in unmet need for contraception and the decision to stop childbearing in Uganda," Studies in Family Planning, vol. 31, no. 2, pp. 124-137, 2000.

[32] N. Dodoo, "Men matter: additive and interactive gendered preferences and reproductive behavior in Kenya," Demography, vol. 35, no. 2, pp. 229-242, 1998.

[33] A. E. Biddlecom and B. M. Fapohunda, "Covert contraceptive use: prevalence, motivations, and consequences," Studies in Family Planning, vol. 29, no. 4, pp. 360-372, 1998.

[34] S. Bharat and V. S. Mahendra, "Meeting the sexual and reproductive health needs of people living with HIV: challenges for health care providers," Reproductive Health Matters, vol. 15, supplement 29, pp. 93-112, 2007.

[35] S. Newmann, K. Mishra, E. A. Bukusi et al., "Integration of family planning into HIV care in Nyanza Province, Kenya: what do providers think?,". In press.

[36] J. F. Phillips, W. L. Greene, and E. F. Jackson, Lessons from Community-Based Distribution of Family Planning in Africa, Population Council, New York, NY, USA, 1999, http:// www.popcouncil.org/pdfs/wp/121.pdf.

[37] J. Harries, D. Cooper, L. Myer, H. Bracken, V. Zweigenthal, and P. Orner, "Policy maker and health care provider perspectives on reproductive decision-making amongst HIV-infected individuals in South Africa," BMC Public Health, vol. 7, article 282, 2007.

[38] N. Rutenberg and C. Baek, "Field experiences integrating family planning into programs to prevent mother-to-child transmission of HIV," Studies in Family Planning, vol. 36, no. 3, pp. 235-245, 2005. 


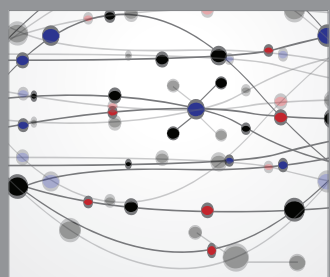

The Scientific World Journal
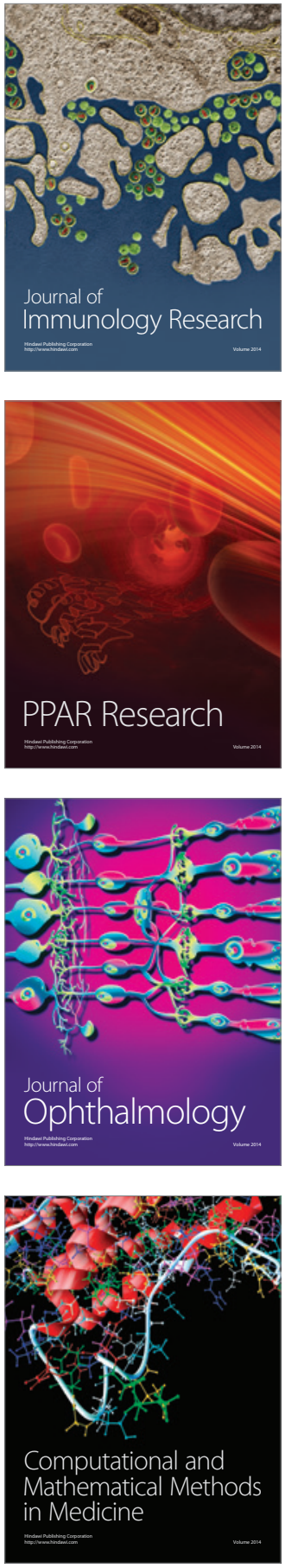

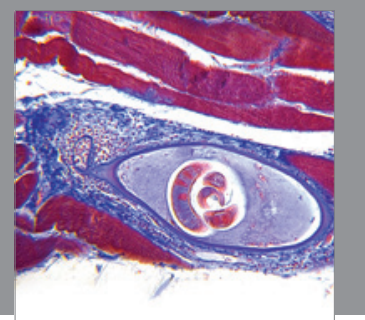

Gastroenterology

Research and Practice
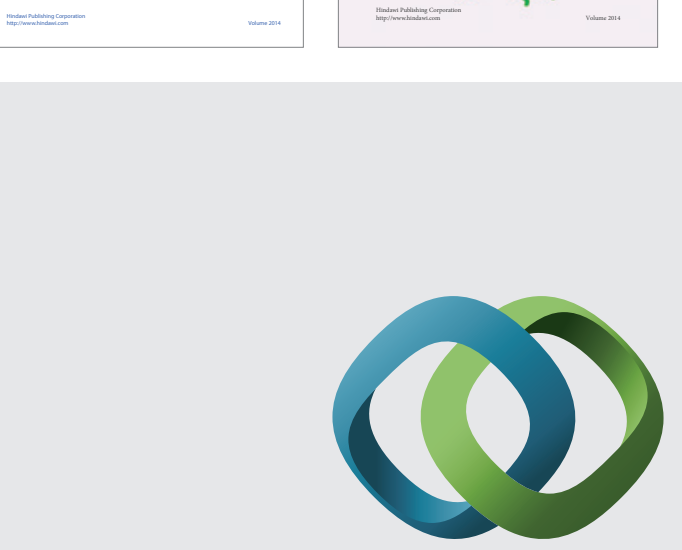

\section{Hindawi}

Submit your manuscripts at

http://www.hindawi.com
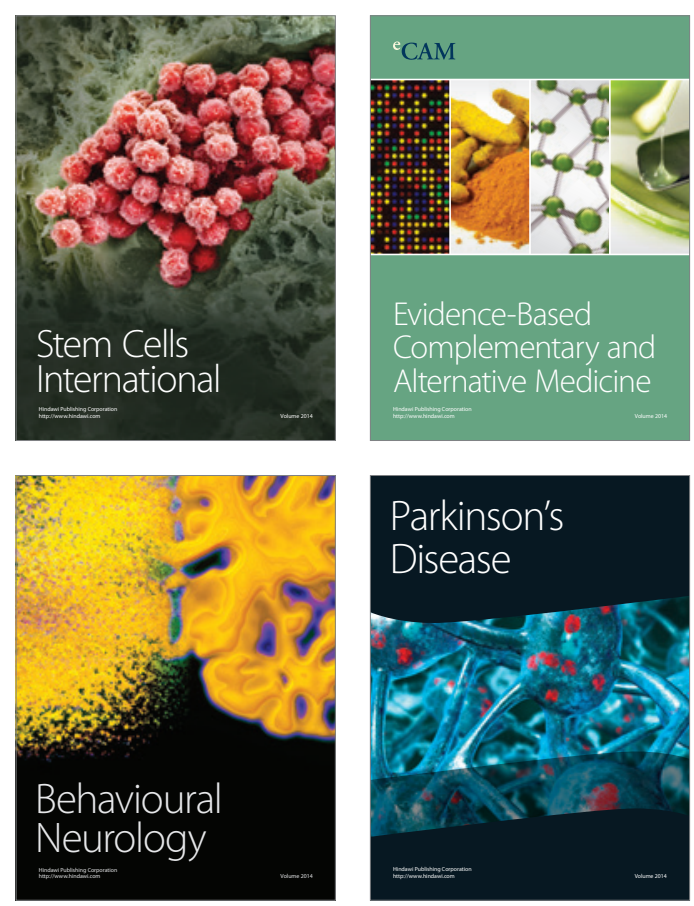

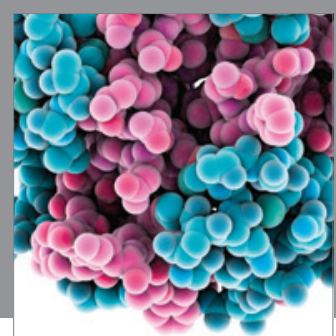

Journal of
Diabetes Research

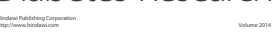

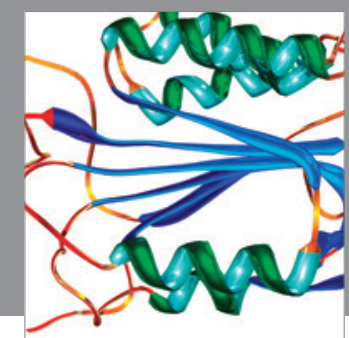

Disease Markers
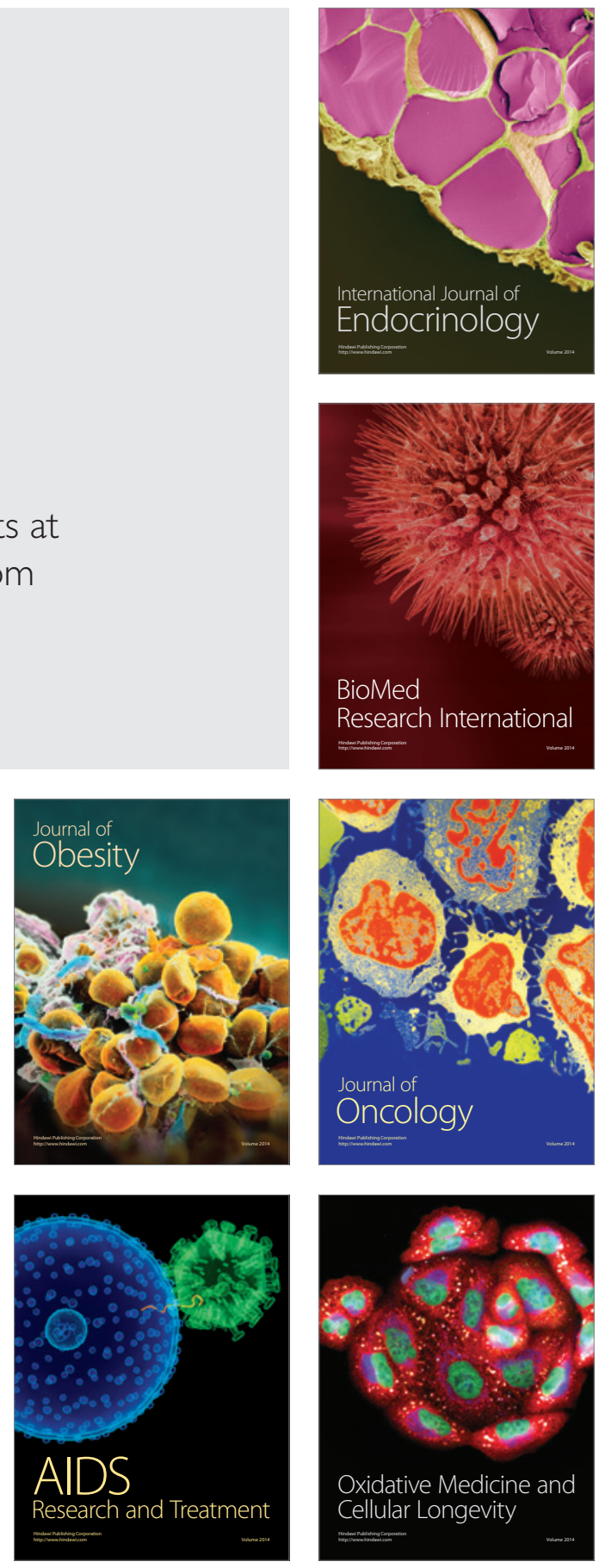